\title{
An Experimental Study to Evaluate the Efficacy of Selected Topical Applications on Induration caused by IV Infiltration among Hospitalized Children in a Tertiary Care Hospital, Pune
}

\author{
Maj Jaya Rakshit \\ Lecturer, MSc Child Health Nursing
}

\begin{abstract}
Objectives: To assess the induration caused by IV infiltration among children. To evaluate and compare the efficacy of selected topical applications i.e. glycerine, MgSO4 and combination of glycerine and MgSO4 paste on induration caused by IV infiltration in hospitalized child. Methodology: A quasi- experimental study was conducted among 40 hospitalized children below the age of 5 years in a tertiary care setting of Pune, of which 10 each were assigned to three respective experimental groups and one control group. The three experimental groups received glycerine, $\mathrm{MgSO}_{4}$ and combination of glycerine and $\mathrm{MgSO}_{4}$ respectively as topical application whereas the control group received placebo treatment. The assessment of IV induration was done using standardized IV Infiltration Scale by Infusion Nurses Society. The resolution of IV induration in experimental groups were measured and compared against the placebo treatment in control group. Results: Most of the children who developed induration were male, below the age of 1 year and had IV cannula present at the sites like right arm, right forearm or left wrist and left arm with maximum children developing IV induration on 2-3 day of IV therapy. Experimental group who received combination of glycerine and $\mathrm{MgSO}_{4}$ was seen to produce statistically significant difference in reduction of signs of IV induration - blanch, induration, skin temperature and pain as compared to other groups Conclusion: Findings of the study indicate that combination of glycerine and $\mathrm{MgSO}_{4}$ paste was more effective than other experimental and control groups in reducing IV induration among sample population.
\end{abstract}

Keywords: Induration, IV infiltration, selected topical applications

\section{Introduction}

An intravenous infiltration injury to a child while in a hospital can be devastating. When we place an infant in the care of a nursing professional, we trust that every precaution will be taken to ensure the child's safety. Often children cry because of the presence of the IV line as it hurts, but the health team members usually attribute their crying to something else and fail to initiate measures to monitor the IV sites periodically. As a result, induration caused by IV infiltration can go undetected for a longer period of time, if timely assessment of IV site is not done. Moreover, IV infiltration injuries in children are difficult to detect as compared to injuries in adults owing to children's inability to express.

Infusion therapy is one of the most common procedures performed in the hospitalized patient. Particularly in neonatal intensive care units almost $100 \%$ patients receive infusion therapy. ${ }^{1}$ With advancement in medical practice intravenous therapy is now considered to be the portfolio for nurses having to manage intravenous cannulation, maintaining patency of IV line, monitoring infusion preparations, drug administrations, etc.

In hospital practice, intravascular lines are used for various purposes in order to administer routine and emergency drugs and fluids in those children who are expected to have gross fluid and electrolyte imbalance. As nurses have a growing responsibility in intravenous therapy and its management, it is important that they anticipate the associated health risks, particularly those associated with peripheral intravenous cannulation.
One of the common problems encountered in intravenous fluid administration is the infiltration of the fluids into tissues near the point of entry of the catheter into the vein. Effects of fluid and drug infiltration from peripheral IV lines vary depending on the following points:-

1) The agent, concentration and volume of the drug or solution infiltrated.

2) Length of exposure after infiltration occurs, especially when the child is unable to verbalize the discomfort of pain, edema or pressure.

3) Anatomical position of the IV cannula (site of cannula insertion whether in joints, dorsal palm, etc.).

4) Mechanical compression caused by electronic infusion pumps.

5) Age group of the child (whether premature infants, neonates, young children), as children are more susceptible to IV infiltration injuries than adults. ${ }^{2}$

The first sign of possible leakage of IV fluids or drugs into the tissues are pain and discomfort. Among other health team members nurse has the key role in reducing the risk of infiltration and extravasation, through prompt and alert monitoring of children with IV cannulation and those receiving intravenous administration of drugs by bolus injection or infusion. The nurse must also be able to recognize the early signs and symptoms of infiltration and extravasation and act swiftly and effectively to limit tissue damage.

\section{Literature Survey}

A survey in 2004 of regional neonatal intensive care units in the United Kingdom recorded the prevalence of infiltration 


\section{International Journal of Science and Research (IJSR) \\ ISSN (Online): 2319-7064 \\ Index Copernicus Value (2013): 6.14 | Impact Factor (2014): 5.611}

injury resulting in skin necrosis as 38 per 1,000 neonates with $70 \%$ of these injuries occurring in infants of 26 weeks' gestation or less. $^{3}$

Robin CK in his study mentioned that preterm newborns are at increased risk for extensive wounding owing to fragile vessels, thin epidermis, and limited subcutaneous tissue over common sites for placement of peripheral IV cannulas. When prevention techniques fail, immediate recognition of the infiltration, prompt intervention and initiation of wound care are important nursing interventions to limit tissue damage. There exists no consensus regarding immediate treatment or optimal wound care after an IV infiltration in the newborn, information in the literature is limited to anecdotal or descriptive case reports. This lack of scientific evidence results in regional and unit-based protocols that vary greatly from hospital to hospital. ${ }^{4}$

Warren D conducted a study in 2011 on implementation of a protocol for the prevention and management of extravasation injuries in the neonatal intensive care unit to determine nurses' understanding and management of young infants with intravenous therapy. There were three specific aims: improve identification and management of extravasation injuries in neonates, ensure management of extravasation injuries in neonates as classified according to IV extravasation staging guidelines and develop a protocol that outlined actions required to manage extravasations. The study observed poor compliance of management of extravasation among the nurses and also identified five barriers related to education of staff and the development of a protocol for the prevention and management of extravasation injuries in the neonatal population. ${ }^{5}$

In a prospective study conducted in the year 2007 in Iran, Nassaji- Zaverah $\mathrm{M}$, et al aimed to investigate the incidence of phlebitis and important related factors causing t hem. The study inferred that phlebitis occurred in $26 \%$ of patients but was not significantly related to age and catheter bore size, but the risk factors included gender, site and type of insertion of catheter as well as presence of infectious diseases. ${ }^{6}$

\section{Materials and Methods}

A quasi- experimental study was conducted among 40 hospitalized children below the age of 5 years in a tertiary care setting of Pune, of which 10 each were assigned to three respective experimental groups and one control group. The three experimental groups received glycerine, $\mathrm{MgSO}_{4}$ and combination of glycerine and $\mathrm{MgSO}_{4}$ respectively as topical application whereas the control group received placebo treatment. The assessment of IV induration was done using standardized IV Infiltration Scale by Infusion Nurses Society (2006). The resolution of IV induration in experimental groups were measured and compared against the placebo treatment in control group.

\section{Results}

- Out of 40 sample, $47.50 \%$ (19) were of the age group less than $1 \mathrm{yr}, 37.50 \%$ (15) were between 4-5 yrs of age and $15 \%$ (6) were of the age group 2-3 yrs. This data indicates that children below the age group of $1 \mathrm{yr}$ and between 4-5 yrs are more prone for developing IV induration.

- Majority i.e., $70 \%$ (28) of sample were male, while rest i.e., 30 \% (12) were female.

- The most common infiltrated site of IV cannula (17.5\%) were dorsal aspect of right arm and forearm, the second most common being left wrist, dorsal and ventral aspect of $\operatorname{arm}(15 \%)$ whereas few i.e., $2.5 \%$ were present in right wrist, dorsum of right and left feet and ankle. These data highlights that IV site more prone for IV induration is right forearm and right dorsal aspect of arm.

- Maximum i.e., 20(50 \%) sample who developed IV induration with IV fluids received isotonic solutions while minimum i.e., 4(10\%) received hypotonic solutions. This data describes that isotonic solution was more contributing towards IV induration as compared to other types of IV fluids in the study sample.

- Among sample who were treated with IV antibiotics, 32.5 \% (13) received Inj Cefotaxime, $27.5 \%$ (11) received Inj Gentamicin and only $2.5 \%$ (1) were treated with Inj Vancomycin. The above data signifies the role of Inj Cefotaxime in causing IV induration as compared to other IV antibiotics in the study.

- Most of the sample i.e., $40 \%$ (16) had IV therapy for 2 days, $37.5 \%$ (15) had IV therapy for 3 days, whereas only $10 \%$ (4) had IV therapy for more than 3 days. These data infers that maximum sample who developed IV induration were on IV therapy for 2-3 days whereas sample who were on IV therapy for less than 3 days developed minimal IV induration.

- The mean and SD of pre treatment blanch in group II and Group III was $(\mathrm{M}=0.90, \mathrm{SD}=0.32)$ and $(\mathrm{M}=0.80, \mathrm{SD}=$ 0.42 ) respectively which reduced significantly on post treatment Day $1(\mathrm{M}=0.30, \mathrm{SD}=0.48)$ and Day $2(\mathrm{M}=0$, $\mathrm{SD}=0$ ) in Group III whereas in Group II the respective values were $(M=0.90, S D=0.32)$ on Day 1 and $(M=0.10$, $\mathrm{SD}=0.32$ ) on Day 3 . Thus it can be stated that there is significant difference in reduction of blanch caused by IV infiltration between experimental Group III (combination of glycerine- $\left.\mathrm{MgSO}_{4}\right)$ and Group II $\left(\mathrm{MgSO}_{4}\right)$ as $\mathrm{p}<0.05$.

- There is highly significant difference in reduction of induration between Group III and Group IV on post treatment day 2 and 3 as $\mathrm{p}<0.0001$, which is also evident from difference in mean and SD of pretreatment induration of Group III ( $\mathrm{M}=3.55, \mathrm{SD}=0.86)$ and Group IV $(\mathrm{M}=3.30, \mathrm{SD}=0.59)$ with post treatment Day 2 in both the groups.

- The mean and SD of pre treatment skin temperature in group II and Group III was $(\mathrm{M}=1.70, \mathrm{SD}=0.48)$ and $(\mathrm{M}=$ $1.40, \mathrm{SD}=0.69)$ respectively which reduced significantly on post treatment Day $1(\mathrm{M}=0.50, \mathrm{SD}=0.85)$ and Day $2(\mathrm{M}=0, \mathrm{SD}=0)$ in Group III whereas in Group II the respective values were $(\mathrm{M}=1.70, \mathrm{SD}=0.48)$ on Day 1 and $(\mathrm{M}=0.10, \mathrm{SD}=0.32)$ on Day 3 . Thus it can be stated that there is significant difference in reduction of skin temperature caused by IV infiltration between experimental Group III (combination of glycerine$\left.\mathrm{MgSO}_{4}\right)$ and Group II $\left(\mathrm{MgSO}_{4}\right)$ on day 1 as $\mathrm{p}<0.05$.

- There is significant difference in reduction of pain between Group III and Group IV on post treatment day 1 as $p<0.05$, which is also evident from difference in mean and SD of pretreatment pain of Group III $(\mathrm{M}=0.90, \mathrm{SD}=$ 


\section{International Journal of Science and Research (IJSR) \\ ISSN (Online): 2319-7064 \\ Index Copernicus Value (2013): 6.14 | Impact Factor (2014): 5.611}

0.32) and Group IV $(\mathrm{M}=0.90, \mathrm{SD}=0.32)$ and with post treatment pain difference on Day 1 in both the groups were: Group III $(\mathrm{M}=0.30, \mathrm{SD}=0.48)$ and Group IV $(\mathrm{M}=$ $0.90, \mathrm{SD}=0.32$ ) respectively.

\section{Discussion}

Total number of sample included in the study was 40 of which 10 each were assigned to three respective experimental groups and one control group. Most of the sample were below the age of 1 year, male and had IV cannula present in right arm, forearm or left wrist and arm. The most common IV fluid received was isotonic solution and commonest IV antibiotic administered was found to be Inj Cefotaxime and Inj Gentamicin with maximum sample developing IV induration on day 2-3 of IV therapy.

Experimental group III i.e. combination of glycerine and $\mathrm{MgSO}_{4}$ was seen to produce highly significant difference in reduction of signs of IV induration: blanch, induration, skin temperature and pain as compared to other experimental treatments and placebo treatment, thus rejecting the null hypothesis $\left(\mathrm{H}_{0 \mathrm{c}}\right)$ and accepting the null hypothesis $\left(\mathrm{H}_{0 \mathrm{a}}\right),(\mathrm{H}$ $\left.{ }_{0 \mathrm{~b}}\right),\left(\mathrm{H}_{0 \mathrm{~d}}\right)$ at a level of significance of $\mathrm{p}<0.05$.

\section{Conclusion}

Following findings were drawn from the findings of the study:-

a) Maximum sample in the study were of age group less than 1year and most of them were male.

b) The prominent IV cannula site for occurrence of IV induration in most of the study sample was right dorsal aspect of arm and forearm and wrist, dorsal and ventral aspect of left arm.

c) Commonest IV fluid causing induration among the sample was isotonic solution and IV injection most responsible was found to be Inj Cefotaxime and Inj Gentamicin.

d) Development of IV induration was more among sample who received IV therapy for more than 2-3 days.

e) Experimental group III i.e. combination of glycerine and $\mathrm{MgSO}_{4}$ was seen to produce highly significant difference in reduction of signs of IV induration: blanch, induration, skin temperature and pain as compared to other treatment and control group.

\section{References}

[1] Sandy SB, Anne S. Neonatal infusion therapy: preventing complications and improving outcomes. Newborn and Infant Nursing Reviews 2006 Dec;6(4):193-01.

[2] Laura LK. Treatment of intravenous infiltration in a neonate. J Pediatric Health Care 2010;24(3):184-8.

[3] Ramasethu J. Prevention and management of extravasation injuries in neonates. NeoReviews 2004 Nov;5(11):491-7.

[4] Robin CK. Wound care after peripheral intravenous extravasation: what is the evidence? 2006 Dec;6(4):20211.
[5] Warren D. Implementation of a protocol for the prevention and management of extravasation injuries in the neonatal intensive care patient. International Journal of Evidence- Based Healthcare 2011 Jun;9(2):165-71.

[6] Nahirya P, Byarugaba J, Kiguli J, Kaddu- Mulindwa D. Intravascular catheter related infections in children admitted on the pediatric wards of Nulago hospital, Uganda. African Health Sciences 2008;8(4).

[7] Nassaji- Zaverah M, Ghorbani R. Peripheral intravenous catheter- related phlebitis and related risk factors. Singapore Med J 2007;48(8):733-6.

[8] Malach T, Jerassy Z, Rudensky B, Schlesinger Y, Broide E, Olsha $\mathrm{O}$ et al. Prospective surveillance of phlebitis associated with peripheral intravenous catheters. American Journal of Infection Control 2006 Jun;34(5):308-12.

[9] Kagel EM, Rayan GM. Intravenous catheter complications in the hand and forearm. Journal of Trauma- Injury Infection \& Critical Care 2004 Jan;56(1):123-7.

[10] 10. Lamagna P, MacPhee M.Trouble shooting pediatric peripheral IVs: phlebitis and infiltration. Nurse week Newsletter 2004 Jun 28

[11]11. Barbut F, Pistone T, Guiguet M, Gaspard R, Rocher $\mathrm{M}$, Dousset $\mathrm{C}$ et al. Complications due to peripheral venous catheterization- prospective study. Preese Med. 2003 Mar 15;32(10):450-6.

[12] 12. Tagalakis V, Kahn SR, Libman M, Blostein M. The epidemiology of peripheral vein infusion thrombophlebitis: a critical review. The American Journal of Medicine 2002 Aug 1;113(2):146-51.

[13] 13. Periera RC, Zanetti ML. Complications resulting from intravenous treatment in surgical patients. Rev Lat Am Enfermagem 2000 Oct;8(5):21-7.

[14] Soifer NE, Borzak S, Edlin BR, Weinstein RA. Prevention of peripheral venous catheter complications with an intravenous therapy team: a randomized controlled trial. Arch Intern Med 1998 Mar 9;158(5):473-7.

[15] Martinez JA, Fernandez P, Rodriguez E, Sobrino J, Torres M, Nubiola A et al. Intravenous cannulae: complications arising from their use and analysis of their predisposing factors. Med Clin (Barc) 1994 Jun 18;103(3):89-93.

[16] Ena J, Cercenado E, Martinez D, Bouza E. Crosssectional epidemiology of phlebitis and catheter related infections. Infect Control Hosp Epidemiol 1992 Jan;13(1):15-20.

[17] Garland JS, Dunne WM, Havens P, Hintermeyer M, Bozzette MA, Wincek $J$ et al. Peripheral intravenous catheter complications in critically ill children: a prospective study. Pediatrics 1992 Jun;89(6/2):1145-50.

[18] Hessov IB. Prevention of infusion thrombophlebitis. Acta Anaesthesiologica Scandinavica 1985 Dec;29(82):33-7.

[19]Richard CM, McCann D, Munnings, McGra RM. Routine resite of peripheral intravenous devices every 3 days did not reduce complications compared with clinically indicated: a randomised controlled trial. BMC Med 2010 Sep 10;53(8).

[20] Nishanth S, Sivaram G, Kalayarasan R, Kate V, Ananthakrishnan N. Does elective re- siting of intravenous cannulae decrease peripheral 


\section{International Journal of Science and Research (IJSR) \\ ISSN (Online): 2319-7064}

Index Copernicus Value (2013): 6.14 | Impact Factor (2014): 5.611

thrombophlebitis? A randomised controlled study. Natl Med J India 2009;22:60-2.

[21] Webster J, Lloyd S, Hopkins T, Osborne S, Yaxley M. Developing a research base for intravenous peripheral cannula re- sites (DRIP trial).A randomised controlled trial of hospital in- patients. International Journal of Nursing Studies 2007;44:664-71

[22] Barker P, Anderson ADG, MacFie J. Randomised clinical trial of elective re- siting of intravenous cannulae. Ann R Surg Engl 2004;86:281-3.

[23] Gupta P, Rai R, Basu S, Faridi MMA. Life span of peripheral intravenous cannula in a neonatal intensive care unit of a developing country. Journal of Pediatric Nursing 2003 Aug;18(4):287-92.

[24] Catney MR, Hillis S, Wakefield B, Simpson L, Domino L, Keller $\mathrm{S}$ et al. Relationship between peripheral intravenous catheter dwell time and the development of phlebitis and infiltration. Journal of Infusion Nursing 2001 Sep- Oct;24(5):332-41.

[25] Bregenzer T, Conen D, Sakmann P, Widmer AF. Is routine replacement of replacement of peripheral intravenous catheters necessary? Arch Intern Med 1988 Jan26;158(2):151-6. 